\title{
Perspectivas dos acadêmicos quanto ao curso de Enfermagem
}

Academic perspectives as to the Nursing course

Perspectivas académicas sobre el curso de Enfermería

Recebido: 19/05/2020 | Revisado: 21/05/2020 | Aceito: 26/05/2020 | Publicado: 08/06/2020

\section{Natália Rayanne Souza Castro}

ORCID: https://orcid.org/0000-0002-9164-3428

Universidade Federal do Amazonas, Brasil

E-mail: natalianne1@hotmail.com

Andre Nascimento Honorato Gomes

ORCID: https://orcid.org/0000-0002-8330-4987

Universidade Federal do Amazonas, Brasil

E-mail: andrenhg@gmail.com

Camila Souza de Araújo

ORCID: https://orcid.org/0000-0002-5416-9819

Universidade Federal do Amazonas, Brasil

E-mail: souzacamila123@hotmail.com

Gilsirene Scantelbury de Almeida

ORCID: https://orcid.org/0000-0003-2153-5330

Universidade Federal do Amazonas, Brasil

E-mail: gscantelbury@gmail.com

Nair Chase da Silva

ORCID: https://orcid.org/0000-0002-5880-4138

Universidade Federal do Amazonas, Brasil

E-mail: nairchase@yahoo.com.br

José Ricardo Ferreira da Fonseca

ORCID: https://orcid.org/0000-0003-1131-3902

Universidade Federal do Amazonas, Brasil

E-mail: jricardoff@hotmail.com 


\title{
Resumo
}

Objetivo: Identificar as expectativas dos acadêmicos ao entrar no curso de Enfermagem de uma Instituição de Ensino Superior (IES) no Amazonas. Método: Pesquisa transversal, descritiva, exploratória, com abordagem qualitativa. A estratégia adotada para obtenção dos dados foi a entrevista semiestruturada realizada em 2018. Os dados foram avaliados através da análise de conteúdo de Bardin. Resultados: realizou-se a caracterização do perfil dos acadêmicos ingressantes de enfermagem, traçou-se suas expectativas em relação ao curso, avaliou-se seus conhecimentos e as expectativas em relação a unidade e IES ao qual estão matriculados e a percepção da família acerca da escolha do estudante pela enfermagem como profissão. Considerações finais: Apesar da importância da temática desenvolvida, ainda há poucos estudos atualizados conhecendo as expectativas em relação ao curso de Enfermagem pelos estudantes. Nesse sentido, tornou-se relevante e contribuinte para a área da enfermagem identificar quais são as expectativas dos acadêmicos ingressantes no curso, pois permitiu conhecer como poderá se dar a trajetória tanto acadêmica quanto profissional.

Palavras-chave: Enfermagem; Estudantes de Enfermagem; Percepção; Bacharelado em Enfermagem; Coleta de dados; Educação Superior; Ensino.

\begin{abstract}
Objective: To identify the expectations of academics when entering the Nursing course at a Higher Education Institution (HEI) in Amazonas. Method: Cross-sectional, descriptive, exploratory research with a qualitative approach. The strategy adopted to obtain the data was the semi-structured interview carried out in 2018. The data were evaluated through Bardin's content analysis. Results: the profile of the nursing undergraduate students was characterized, their expectations were outlined in relation to the course, their knowledge and expectations were evaluated in relation to the unit and HEI to which they are enrolled and the family's perception of the student's choice for nursing as a profession. Final considerations: Despite the importance of the theme developed, there are still few updated studies knowing the expectations regarding the Nursing course by students. In this sense, it became relevant and contributing to the area of nursing to identify what are the expectations of students entering the course, as it allowed them to know how the academic and professional trajectory can take place.
\end{abstract}

Keywords: Nursing; Nursing students; Perception; Bachelor of Nursing; Data collect; College education; Teaching. 


\section{Resumen}

Objetivo: identificar las expectativas de los académicos al ingresar al curso de Enfermería en una Institución de Educación Superior (IES) en Amazonas. Método: investigación transversal, descriptiva, exploratoria con enfoque cualitativo. La estrategia adoptada para obtener los datos fue la entrevista semiestructurada realizada en 2018. Los datos se evaluaron mediante el análisis de contenido de Bardin. Resultados: se caracterizó el perfil de los estudiantes de pregrado de enfermería, se describieron sus expectativas en relación con el curso, se evaluaron sus conocimientos y expectativas en relación con la unidad y la IES a la que están inscritos y la percepción de la familia sobre el curso. La elección del estudiante de enfermería como profesión. Consideraciones finales: a pesar de la importancia del tema desarrollado, todavía hay pocos estudios actualizados que conozcan las expectativas con respecto al curso de Enfermería por parte de los estudiantes. En este sentido, se volvió relevante y contribuyó al área de enfermería identificar cuáles son las expectativas de los estudiantes que ingresan al curso, ya que les permitió saber cómo puede tener lugar la trayectoria académica y profesional.

Palabras clave: Enfermería; Estudiantes de Enfermería; Percepción; Licenciatura en Enfermería; Recolección de datos; Educación universitaria; Enseñanza.

\section{Introdução}

A Instituição de Ensino Superior (IES) permite transformações nas esferas de desenvolvimento pessoal, social, cultural, cognitivo, afetivo e principalmente no profissional, de forma a também gerar expectativas no que diz respeito a tão esperada escolha pelo curso de graduação realizada pelo ingressante nesta nova etapa de sua vida (Ramos et al., 2015).

Ao ingressar no ensino superior, o estudante traz consigo expectativas e perspectivas, quer sejam positivas quanto negativas, muitas das vezes acompanhadas por sentimentos de ansiedade, medos, dúvidas e anseios. Este novo ambiente de envolvimento tanto no ensino, na pesquisa, extensão, bem como a interação com outros estudantes, docentes, comunidade, juntamente com as expectativas que este estudante traz consigo, podem interferir de forma benéfica ou não na sua construção acadêmica e profissionalizante (Ibidem, 2015).

Os cursos de graduação de Enfermagem são fundamentados em um currículo atualizado e com uma abordagem integradora, baseado em diretrizes curriculares que trazem consigo embasamentos para a construção de planos pedagógicos de curso, visando despertar o pensamento crítico e reflexivo do ingressante. Isso permite uma organização dos conteúdos 
fundamentada em uma integração teórica e prática dos conteúdos, o que inclui uma interdisciplinaridade do aluno no ensino, pesquisa e extensão ao decorrer do seu processo de formação profissional (Borges, Vannuchi \& González, 2010).

Em um estudo comparativo feito com acadêmicos de enfermagem de universidades tanto pública quanto privada acerca da opção profissional escolhida, o crescente e variado mercado de trabalho na enfermagem e a chance de um salário melhor são algumas das expectativas levantadas pelos acadêmicos na instituição privada. Os estudantes na instituição pública, ao ingressar no curso de enfermagem desconhecem em grande parte a profissão escolhida, surgindo assim a perspectiva que a enfermagem é a área que proporciona ajuda as outras pessoas (Spindola et al., 2011).

Para Davok \& Bernard (2016) conhecer as perspectivas e expectativas do aluno sobre a IES permite identificar as prováveis causas relacionadas a evasão no curso escolhido, bem como subsidiar informações para o planejamento de políticas e planos institucionais que visem a permanência e melhor aproveitamento no ensino, pesquisa e extensão oferecidos pela universidade aos alunos.

Essas instituições formadoras possuem como responsabilidade conhecer as perspectivas dos acadêmicos, pois desta forma poderão direcionar ações que visem ampliar a adaptação desses alunos permitindo a integração dos acadêmicos ao curso que realizam; assim poderão intervir em fatores que podem interferir na qualidade de ensino e aprendizagem ofertados por ela. Além disso, torna-se pertinente avaliar como está se dando a satisfação acadêmica dos ingressantes de enfermagem, de forma a garantir uma educação eficaz e de qualidade, bem como beneficiar o exercício de um profissional.

O objetivo deste estudo foi identificar as expectativas dos acadêmicos ao entrar no curso de Enfermagem de uma IES pública no Amazonas, buscando saber quais fatores influenciam para a criação das expectativas do aluno no curso de Enfermagem e investigar o que o acadêmico espera do curso.

\section{Metodologia}

Estudo transversal, descritivo, exploratório, de natureza qualitativa como preconiza Pereira et al. (2018), com a finalidade de conhecer as expectativas dos acadêmicos de enfermagem quanto ao seu processo de formação.

Este projeto faz parte de um projeto de pesquisa maior com o propósito de traçar o perfil dos acadêmicos de enfermagem ingressantes no curso, conhecer as razões pela opção do 
curso e suas expectativas quanto ao processo de formação, foi aprovado no CEP sob o número do CAAEE: 83574318100005020, diante disto trabalhou-se um dos objetivos do projeto que é: Identificar as expectativas dos acadêmicos ao entrar no curso de Enfermagem de uma Instituição de Ensino Superior no Amazonas.

O universo deste estudo é composto pelos 56 alunos ingressantes, matriculados no primeiro período do curso de enfermagem de uma Instituição de Ensino Superior - IES, pública. A amostra desse estudo foi de 37 alunos ingressantes no curso de enfermagem no ano de 2018 na IES. Considerando que o ingresso de alguns estudantes se deu precocemente, foi solicitado para os menores de 18 anos autorização dos pais/responsáveis legais, que dataram e assinaram o TCLE para a participação de seus dependentes neste estudo.

$\mathrm{O}$ critério de inclusão deste estudo foi ser estudante do $1^{\circ}$ período de graduação em enfermagem. Excluiu-se deste estudo alunos ingressantes no curso em anos anteriores que estejam realizando qualquer disciplina do primeiro período.

O estudo foi realizado nas dependências da IES pública onde os estudantes fazem o curso.

Para a coleta de dados utilizou-se a técnica de entrevista. Como instrumentos de coleta de dados foi utilizado um roteiro de entrevista, contendo inicialmente perguntas com a finalidade de coletar os dados sociodemográficos dos estudantes e em seguida questões buscando conhecer as expectativas com a IES a qual está vinculado no seu processo de formação. A aplicação do instrumento de coleta dados se deu após dar ciência aos acadêmicos sobre os objetivos da pesquisa e obtenção de seu consentimento para participação, por meio da assinatura do TCLE e para aqueles menores de 18 anos, o TCLE foi assinado pelos seus responsáveis legais.

Os dados demográficos para caracterização do perfil dos estudantes de enfermagem foram analisados, tabulados e processados eletronicamente, utilizando o programa SPSS 21.0. Foram utilizadas medidas de tendência central (mediana, valores máximo e mínimo).

Os dados qualitativos foram verificados pela análise de conteúdo de Bardin (Bardin, 2010). Os indivíduos participantes deste estudo foram codificados com numeração entre 1 e 37 conforme ocorreu a entrega do TCLE. Utilizou-se como código na transcrição das respostas a abreviatura de aluno (AL) seguida da codificação.

Quanto as etapas de análise, seguiu-se: 
Pré-análise: consiste organização do material, através da leitura flutuante e em seguida mais precisa, a escolha dos documentos a serem submetidos à análise, a formulação das hipóteses e dos objetivos e a elaboração de indicadores que fundamentem a interpretação final.

Exploração do material: consistenas fases de codificação, classificação (enumeração) e a categorização.

Tratamento dos resultados obtidos, a inferência e a interpretação: visando transformar dados em informações necessárias para a análise.

\section{Resultados}

Caracterização do perfil dos acadêmicos ingressantes de enfermagem:

Em relação aos dados demográficos, obteve-se do estudo uma amostra de 37 alunos ingressantes no curso de Enfermagem, na qual 26 (70,3\%) era do sexo feminino. Após a análise dos dados, verificou-se uma variação entre 17 e 29 anos de idade, com uma mediana de 18 anos.

\section{Expectativas dos estudantes ao ingressar no curso de graduação em enfermagem:}

Os acadêmicos de enfermagem esperam a obtenção de conhecimentos referentes a profissão escolhida, o aprendizado através dos conteúdos abordados nas disciplinas curriculares ofertadas no curso com um ensino de qualidade, a fim de ajudar a si próprio e principalmente a outras pessoas, bem como um bom preparo para o mercado de trabalho, se tornar um profissional habilitado e capacitado. Almejam também a identificação com a área escolhida, a satisfação profissional, o crescimento pessoal, tal como o retorno financeiro.

Estas questões são identificadas em alguns relatos de estudantes que foram entrevistados:

Aprender através dos conteúdos e experiências a ser um profissional habilitado e capacitado.(AL14)

Espero que eu possa me sentir à vontade com o curso e me identifique na área. (AL13)

Espero conseguir uma carreira sucedida, um bom salário, ser feliz na profissão. (AL33) 
Research, Society and Development, v. 9, n. 7, e731974693, 2020

(CC BY 4.0) | ISSN 2525-3409 | DOI: http://dx.doi.org/10.33448/rsd-v9i7.4693

Que me torne uma profissional com uma alta capacidade de respeitar, cuidar e dar assistência tecnicamente a todos que precisam, novas experiências, amigos e futuros companheiros de trabalho. (AL4)

Os resultados dos estudos são semelhantes dos encontrados a partir da questão norteadora aos discentes “O que você espera do curso de enfermagem?”. Segundo a análise temática de Bardin, destacou-se as seguintes categorias: "Aprendizado"; "Identificação com o curso escolhido"; "Crescimento pessoal"; "Realização Profissional"; "Ensino de qualidade"; "Profissional habilitado e capacitado"; "Conhecer e interagir com pessoas novas" e "Retorno Financeiro".

\section{Conhecimento dos estudantes acerca da Escola de Enfermagem de Manaus:}

Este é um momento importante para observar o que o acadêmico conhece sobre o local onde optou por realizar o curso de enfermagem, momento este marcado por pensamentos positivos, mas com concepções de dúvidas e anseios. Para grande parte dos alunos entrevistados, o lugar é considerado conservado, ambiente acolhedor e agradável, antigo, mas de boa estrutura física, tradicional, sendo considerado um dos melhores locais para o ensino e a formação de qualidade, já que é apontado como um ambiente que proporciona aos estudantes a capacitação e o envolvimento no ensino, pesquisa e extensão. Assim, como também há a prevalência de uma parte dos entrevistados que relatam possuir conhecimento pouco ou nenhum sobre a Escola de Enfermagem de Manaus.

Sei que é uma instituição muito bem cuidada e conservada, que proporciona aos seus alunos muita pesquisa e aprendizado, com assistência por parte dos educadores que aqui trabalham. (AL23)

É uma das escolas mais antigas e pela avaliação de pessoas que já estudaram aqui, tem uma ótima estrutura e um ótimo ensino. (AL22)

Sinceramente, este é o primeiro contato que tenho com a instituição e antes da minha aprovação não tinha ouvido falar. (AL10)

Foi fundadora do Conselho de Enfermagem. É criadora de diversos projetos de extensão e possibilita crescimento profissional dos acadêmicos. (AL31) 
Após a questão "O que você sabe sobre a Escola de Enfermagem de Manaus?" Evidenciou-se as categorias: "Conhecimento limitado sobre a Escola de Enfermagem"; "Local antigo e tradicional"; "Lugar conservado, agradável, acolhedor e ótima estrutura"; “Alta capacitação profissional (ensino, pesquisa e extensão) e "Qualidade no ensino".

\section{Expectativas dos estudantes em relação à IES ao qual estão matriculados:}

A IES possui papel fundamental tanto no âmbito pessoal, como no acadêmico e profissional na vida do indivíduo ingressante. É uma unidade formadora que possui o compromisso e a responsabilidade no que se refere as expectativas a serem esperadas e atendidas pelos estudantes vinculados. De acordo com os ingressantes, é esperado um ensino qualificado para a reflexão em uma boa formação profissional, através de aulas didáticas e atualizadas, envolvendo-se em projetos complementares, apoio e auxílios no ensino e financeiro, proporcionando diversas oportunidades no âmbito acadêmico e profissional, prezam também pelo crescimento pessoal e em manter relações interpessoais saudáveis neste ambiente.

Espero que me conceda oportunidades de aprendizado qualificado e que me ajude no mercado de trabalho. (AL13)

Que possa proporcionar as condições necessários para conclusão do curso sem atrasos. (AL8)

O melhor ensino, estrutura e apoio. (AL10)

Ensino de qualidade, auxílios, didáticas dinâmicas e projetos complementares. (AL26)

Ajuda, assistência, aprendizado. (AL36)

Quando questionados "O que você espera da Instituição de Ensino Superior (IES) ao qual está vinculado?" emergiram as seguintes categorias: "Qualidade no ensino"; “Apoio e ajuda"; "Proporcione experiências e oportunidades"; "Relação Saudável entre professores e alunos" e "Crescimento pessoal". 
Percepção da família acerca da escolha do estudante pela enfermagem como profissão:

O vínculo familiar pode desencadear sentimentos tanto concordantes como contrários na escolha exercida pelo ingressante sobre a profissão a ser seguida, visto ser considerado um dos primeiros meios de interação social e de troca de experiências do indivíduo e comunidade. Segundo os discursos dos entrevistados, a maioria de seus familiares aprovaram a escolhapelo curso de enfermagem, apoiaram a decisão e sentiram-se orgulhosos pela conquista de ter sido aprovado em uma universidade pública e por ter optado por um curso ligado a área da saúde, concordando que a escolha realizada pelo acadêmico colabora para uma boa profissão. Contudo, há a percepção por parte dos familiares que a opção por este curso é algo que traz receio, insegurança de um futuro profissional, pois perpetua a ideia da baixa valorização da categoria de enfermagem, refletindo em uma remuneração ruim e com carga de horário elevada. Abaixo os acadêmicos descrevem os sentimentos gerados pelos familiares:

Sentiram-se orgulhosos por escolher a área da saúde. Respeitaram minha escolha desde o início. (AL16)

Eles estão felizes e me incentivam a concluir o curso da melhor maneira possível. (AL26)

Alguns ficaram receosos por acharem que a profissão não é reconhecida, pouco remunerada e com carga horária de trabalho, mas recebi apoio por se tratar de uma área que me identifico e gosto. (AL10)

Nem todos apoiaram, mas eu me apaixonei. (AL25)

A maioria não apoia, duvida à desistência de outro curso. (AL32)

Frente ao questionamento acerca de "O que seus familiares acham de você ter escolhido a enfermagem como profissão?", “Apoiaram”, "Felizes e animados pela escolha”, "Boa escolha profissional", "Familiares não se sentem seguros com a escolha" e "Ficaram orgulhos pela escolha e conquista" foram as categorias que surgiram. 


\section{Discussão}

Um estudo apontou que os jovens ingressantes possuem melhores perspectivas quanto ao curso de enfermagem, pois criam a ideia de que a universidade é um ambiente novo e cheio de oportunidades para melhorias no seu desenvolvimento. Isso reflete no surgimento de boas expectativas no que diz respeito ao desenvolvimento profissional e pessoal, assim como esperam criar amizades, mantendo vínculos afetivos, e o anseio de envolver-se de forma ativa e eficiente nas atividades proporcionadas pelo curso (Ramos et al., 2015).

De acordo com um estudo realizado na universidade pública de Londrina, ao ingressar no curso de enfermagem os alunos trazem consigo alguns anseios e desejos, como a de ajudar e prestar o cuidado ao próximo, adquirir a empatia e identificação pelo curso escolhido, seguindo assim da própria valorização pela atuação profissional a ser prestada pela enfermagem. Já em estudos a níveis internacionais, destacam-se a vontade em adquirir um bom retorno financeiro já que está atuando em um país exterior, a chance de ofertar ajuda e cuidado as outras pessoas, a identificação pela área da saúde e a oportunidade do grande mercado financeiro para a área de enfermagem são uma das motivações esperadas ao optar pela profissão escolhida (Sigaud et al., 2016).

A identificação com a área da saúde, o vasto mercado de trabalho, a oportunidade em adquirir uma agradável remuneração financeira, além da aprovação no processo seletivo ser considerado menos complicado para o ingresso são fatores que levam os alunos a optarem pelo curso de enfermagem (Câmara et al., 2014).

Através de um estudo feito sobre as experiências abordando as atividades desenvolvidas por um Programa denominado Universitário por um dia na Escola de Enfermagem de Ribeirão Preto da Universidade de São Paulo foi possível mostrar a importância das visitas técnicas feitas com estudantes de ensino público para o ambiente de nível superior, afim de ser uma estratégia de aproximar o estudante da realidade da universidade (Gonçalves et al., 2018). Esta prática possibilita o acesso e conhecimento do espaço, a aproximação com as metodologias de ensino e a forte contribuição na motivação do ingresso no ensino superior, bem como incentivando e colaborando para a sua futura permanência neste ambiente de formação.

As motivações do aluno quanto a IES encontram-se relacionadas entre o que esse acadêmico recebe deste cenário e o que é esperado conforme suas idealizações. Desta forma, a qualidade da educação de nível superior envolve não somente a identificação dos níveis de satisfação do estudante com a universidade, mas também está relacionado com a qualidade do 
meio estrutural, a execução e qualificação dos serviços acadêmicos, docentes, técnicoadministrativo, as formas de avaliações institucionais, a exposição das metodologias de ensino, o envolvimento em pesquisa e extensão pelos alunos, e a presença de outros programas, como o de pós-graduação (Hirsch et al., 2015).

A Instituição de Ensino Superior tem-se como uma das obrigações para com os ingressantes o compromisso em instigar o desenvolvimento de habilidades, competências e concepções sob a área a ser exercida pelo envolvidos no futuro campo de trabalho (Câmara $e t$ al., 2014).

Identificar quais são as percepções dos estudantes sobre o serviço ofertados pela a instituição de nível superior, bem como a forma e a qualidade a ser prestada, possibilita assim um acompanhamento de todo o funcionamento e execução das atividades realizadas pela IES, levando em consideração as expectativas positivas ou negativas advindas com os alunos, assim como as futuras experiências a serem desenvolvidas pelos estudantes com os serviços oferecidos, são subsídios para determinar os níveis de satisfação com os serviços executados pela universidade (Braum et al., 2015).

Os níveis de satisfação acadêmica envolvem toda a totalidade desempenhada por uma instituição, como por exemplo a qualidade do ensino e formação do curso no que diz respeito a teoria e prática, das informações recebidas, a forma de avaliação do aprendizado, a relação dos envolvidos no que se refere ao corpo estudantil, docente e os demais envolvidos na prestação e execução dos serviços da instituição, o projeto pedagógico de curso, bem como toda a parte administrativa da universidade e seus compartimentos estruturais e recursais (Ramos et al., 2015).

A família é considerada uma organização social significativa na vida do aluno ingressante, pois através dela surge a exposição de ideias, concepções, crenças, críticas, afirmações e experiências, sendo capaz de interferir ou não na construção da decisão pela escolha da profissão (Romero et al., 2016).

Em um estudo realizado com 72 estudantes matriculados no 1 semestre do curso de bacharelado em enfermagem de uma universidade pública estadual na cidade de São Paulo, surgiram questionamentos acerca do posicionamento dos familiares a respeito da escolha pelo curso de enfermagem, cerca de $(73,6 \%)$ dos estudantes referiram não ter sido influenciado pelos familiares quanto a sua opção pelo curso, e após a escolha, grande parte dos pais apoiaram a decisão, $(39,4 \%)$ dos alunos declaram ter recebido incentivo e respeito, 10,4\% adquiriram sentimentos de admiração por ter escolhido a enfermagem como profissão, havendo também um percentual de $9 \%$ para os familiares que deixam claro que os seus filhos 
deveriam optar por outro curso, e 6,1\% que ainda acreditam que a enfermagem é uma carreira mal remunerada (Sigaud et al., 2016).

A sociedade ainda perpétua uma imagem e concepções com rótulos e preconceitos sobre a enfermagem, e o desconhecimento sobre o real trabalho do enfermeiro reforça a propagação e persistência destes tipos de conceitos. Assim, conhecer o que o acadêmico espera e sabe do curso escolhido pode colaborar para uma decisão mais racional sobre a profissão escolhida.

\section{Considerações Finais}

O presente estudo abordou que as expectativas dos alunos ingressantes no curso de graduação em enfermagem encontram-se relacionadas com a vontade de conhecer a profissão escolhida, identificar e adaptar-se ao curso, conforme os assuntos expostos de maneira dinâmica e estratégica, almejando o crescimento pessoal, a satisfação profissional e estar preparado para o grande mercado de trabalho para que o retorno financeiro também seja alcançado.

O aluno ao ingressar na IES encontra-se na fase de desenvolvimento biológica, psicológica, social, cultural e futuramente científica, já que cada vez mais se dá o ingresso por jovens no curso superior. Estes, por sua vez, trazem consigo sentimentos de certeza pela opção escolhida, ou até mesmo questionamentos, medos, e os anseios gerados pelos pais, família, amigos e sociedade, sendo uma das formas influenciáveis na perspectiva do estudante em relação sua escolha pelo curso, colaborando muitas vezes para indecisão na permanência do curso, contribuindo para o aumento das taxas de evasão, insatisfação pessoal, baixo desempenho acadêmico, ou também dificultando em sua trajetória profissional.

Apesar da importância da temática desenvolvida, ainda há poucos estudos atualizados conhecendo as expectativas em relação ao curso de Enfermagem pelos estudantes. Nesse sentido, tornou-se relevante e contribuinte para a área da enfermagem identificar quais são as expectativas dos acadêmicos ingressantes no curso, pois permitiu conhecer como poderá se dar a trajetória tanto acadêmica quanto profissional.

\section{Referências}

Bardin L. (2010). Análise de conteúdo. 4.ed. Lisboa: Edições70.

Borges, A.G.; Vannuchi, M.T.O.; González, A.D. \& Vannuchi, R.O. (2010). Caracterização e expectativas de estudantes ingressantes de um curso de graduação em enfermagem. Revista 
Espaço para a Saúde, Londrina, 12 (1): 01-06, dez. Disponivel em:

http://espacoparasaude.fpp.edu.br/index.php/espacosaude/article/view/421/pdf.

Braum, L.M.S.; Leão, A.L.D.B.C.; Freire, O.B.L. \& Walter, S.A. (2015). Percepção dos alunos sobre qualidade no Ensino Superior: identificação das prioridades de melhoria no Curso de Ciências Contábeis. Revista de Estudos Contábeis, Londrina, 6(11): 62-80, jul./dez. Disponível em: http://www.uel.br/seer/index.php/rec/article/viewFile/27344/20637.

Câmara, A.G.; Germano, R.M.; Valença, C.N.; Malveira, F.A.S.; Pinto, D.P.S.R. \& Cossi, M.S. (2014). Motivações de estudantes para cursar enfermagem: Entre a empatia e o mercado de trabalho. Rev enferm UFPE on line., Recife, 8(2):346-50, fev. Disponível em: https://periodicos.ufpe.br/revistas/revistaenfermagem/article/download/9680/9724.

Davok DF, Bernard RP (2016). Avaliação dos índices de evasão nos cursos de graduação da Universidade do Estado de Santa Catarina - UDESC. Revista Avaliação, Campinas; Sorocaba, SP, 21(2): 503-21. Disponível em: https://www.scielo.br/pdf/aval/v21n2/19825765-aval-21-02-00503.pdf.

Gonçalves, E.R.; Ferreira, M.V.F.; Santos, J.T.T.; Pitta, N.C.; Pereira, R.M.P \& Fernandes, A.P.M. (2018). Programa Universitário Por Um Dia: conhecendo a Escola de Enfermagem de Ribeirão Preto. Rev Min Enferm. 22:e-1133. Disponível em: http://www.reme.org.br/artigo/ detalhes/1270.

Hirsch, C.D.; Barlem, E.L.D.; Barlem, J.G.T.; Silveira, R.S. \& Mendes, D.P. (2015). Fatores preditores e associados à satisfação dos estudantes de enfermagem. Acta Paul Enferm. 28(6): 566-72. ISSN 1982-0194. Disponível: https://www.scielo.br/scielo.php?script=sci_abstract \&pid=S0103-21002015000600566\&lng=en\&nrm=iso\&tlng=pt. Acesso em: 20 jul. 2019.

Pereira, AS, Shitsuka, DM, Parreira, FJ \& Shitsuka, R. (2018). Metodologia da pesquisa científica. [e-book]. Santa Maria. Ed. UAB/NTE/UFSM. Disponível em: https://repositorio.ufsm.br/bitstream/handle/1/15824/Lic_Computacao_MetodologiaPesquisa-Cientifica.pdf?sequence $=1$. 
Ramos, A.M.; Barlem, J.G.T.; Lunardi, V.L.; Barlem, E.L.D.; Silveira, R.S. \& Bordignon, S.S. (2015). Satisfação com a experiência acadêmica entre estudantes de graduação em enfermagem. Texto Contexto Enferm, Florianópolis, 2015 Jan-Mar; 24(1): 187-95. Disponível em: https://www.scielo.br/pdf/tce/v24n1/pt_0104-0707-tce-24-01-00187.pdf.

Romero, A.I.S.; Williams, A.C.C.; Escalona, M.G.; Quevedo, O.E. \& Pedroso, N.A. (2016). Factores que influyen en la orientación vocacional de estudiantes en Enfermería. Facultad de Ciencias Médicas "Enrique Cabrera". Revista Uruguaya de Enfermería Montevideo, noviembre, 11(2): 2301-371. ISSN On line. Disponível em: http://rue.fenf.edu.uy/index.php/rue/article/view/202/197.

Sigaud, C.H.S.; Souza, N.B.; Nobrega, A.A.; Toriyama, A.T.M. \& Costa, P. (2016). Motivos de estudantes de enfermagem para a escolha da carreira. Rev. iberoam. Educ. investi. Enferm. 6(4):18-24. Disponível em: https://www.enfermeria21.com/revistas/aladefe/articulo/ 218/motivos-de-estudantes-de- enfermagem-para-a- escolha-da-carreira/.

Spindola, T.; Santiago, M.M.A.; Martins, E.R.C. \& Francisco, M.T.R. (2011). Significado da profissão para alunos que ingressam na graduação em Enfermagem. Revista Brasileira de Enfermagem. Rev. bras. enferm. 64(4): 725-31. Brasília. Disponivel em: https://www.scielo.br/scielo.php?script=sci_arttext\&pid=S0034-71672011000400015.

\section{Porcentagem de contribuição de cada autor no manuscrito}

Natália Rayanne Souza Castro - 25\%

Andre Nascimento Honorato Gomes - 25\%

Camila Souza de Araújo - 15\%

Nair Chase da Silva - $15 \%$

Gilsirene Scantelbury de Almeida - 15\%

José Ricardo Ferreira da Fonseca - 5\% 